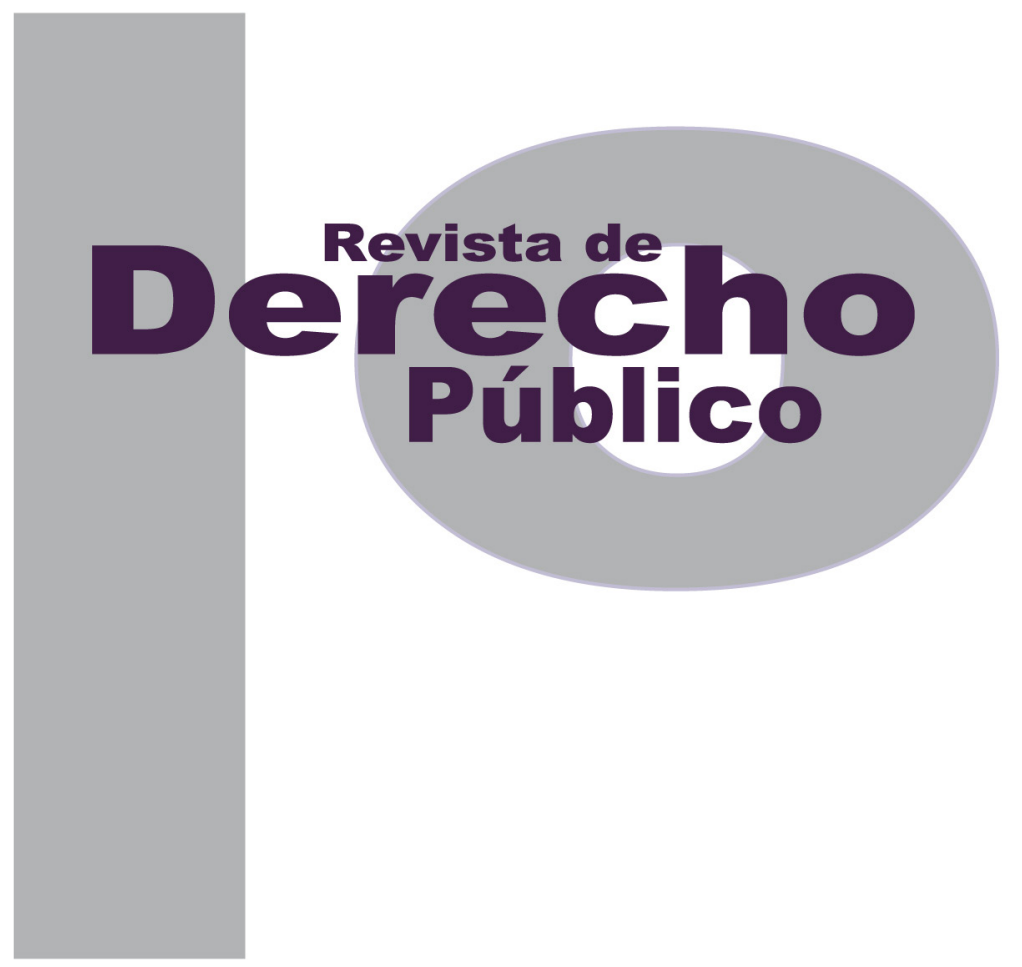

IMPACTO DE LA LEGISLACIÓN EN MATERIA DE MIGRACIÓN EN LA REALIDAD SOCIAL DE INMIGRANTES CENTROAMERICANOS EN SITUACIÓN IRREGULAR EN LA CIUDAD DE MONTERREY (MÉXICO)

\author{
DIANA ROCíO ESPINO TAPIA \\ JUAN ANTONIO DONCEL DE LA COLINA \\ Artículo de investigación científica y tecnológica \\ DOl: http://dx.doi.org/10.15425/redepub.36.2016.12 \\ Universidad de los Andes \\ Facultad de Derecho \\ Rev. derecho publico No. 36 \\ enero - junio de 2016. e-ISSN 1909-7778
}




\title{
Impacto de la legislación en materia de migración en la realidad social de inmigrantes cen- troamericanos en situación irregular en la ciudad de Monterrey (México)
}

\section{Resumen}

Esta investigación tuvo como objetivo analizar la forma en que la legislación vigente en materia de migración y derechos humanos impacta en la realidad social que viven miles de inmigrantes centroamericanos en situación de irregularidad administrativa residentes en Monterrey (México). Para ello se siguió un planteamiento metodológico sociojurídico. Desde la perspectiva jurídica se realizó un análisis de contenido normativo de la Ley de Migración a partir de la reforma constitucional en materia de derechos humanos del 2011. En lo referente a la perspectiva sociológica se llevó a cabo un exhaustivo trabajo de campo aplicando metodología cualitativa. Como resultado, se encontró una evidente ineficacia de la nueva ley por la incongruencia de los hechos con sus objetivos planteados. Se concluyó que para alcanzar estos objetivos se requiere, además, un cambio de cultura jurídica que implique superar la generalizada actitud contramigración en el ámbito institucional.

Palabras claves: migración irregular, derechos humanos, legislación, eficacia, vulnerabilidad.

\section{The impact of Monterrey's legal regulation for Central American migrants in an irregular si- tuation}

\begin{abstract}
This papers aims to provide a socio-legal account of the impact of Monterrey's legal regulation on migrants and human rights in the lives of thousands of migrants in an irregular situation coming from Central American. On the one hand, the Law on Migration was analyzed from the perspective of the human rights constitutional reform of 2011. On the other hand, a qualitative research was done, finding evidence of the inefficacy of the new law. It is argued that the attainment of the new law objectives' requires a change in the anti-migrant institutional legal culture.
\end{abstract}

Key words: migration; human rights; legislation; efficacy; vulnerability.

\section{Impacto da legislação em matéria de migração na realidade social de imigrantes centro- americanos em situação irregular na cidade de Monterrey (México)}

\section{Resumo}

Esta investigação teve como objetivo analisar a forma em que a legislação vigente em matéria de migração e direitos humanos impacta na realidade social que vivem milhares de imigrantes centro-americanos em situação de irregularidade administrativa residentes em Monterrey (México). Para isso se seguiu um enfoque metodológico sócio jurídico. Desde a perspectiva jurídica foi realizada uma análise de conteúdo normativo da Lei de Migração a partir da reforma constitucional em matéria de direitos humanos de 2011. No referente à perspectiva sociológica foi realizado um exaustivo trabalho de campo aplicando metodologia qualitativa. Como resultado, se encontrou uma evidente ineficácia da nova lei pela incongruência dos fatos com seus objetivos apresentados. Concluiu-se que para alcançar estes objetivos se requer, além disso, uma mudança de cultura jurídica que implique superar a generalizada atitude contra migração no âmbito institucional.

Palavras-chaves: migração irregular, direitos humanos, legislação, eficácia, vulnerabilidade. 


\title{
Impacto de la legislación en materia de migración en la realidad social de inmigrantes centroamericanos en situación irregular en la ciudad de Monterrey (México)*
}

\author{
DIANA ROCÍO ESPINO TAPIA** \\ JUAN ANTONIO DONCEL DE LA COLINA***
}

\begin{abstract}
SUMARIO
Introducción - I. METODOLOGÍA - II. RESULTADOS - A. Marco jurídico de la migración en México - B. Problemática desde la perspectiva institucional: el enfoque mesosociológico - C. Problemática desde la perspectiva de sus protagonistas: el enfoque microsociológico - III. CONCLUSIONES - Referencias.
\end{abstract}

* Cómo citar este artículo: Espino Tapia, D. R. y Doncel de la Colina, J. A. (Junio, 2016). Impacto de la legislación en materia de migración en la realidad social de inmigrantes centroamericanos en situación irregular en la ciudad de Monterrey (México). Revista de Derecho Público, (36). Universidad de los Andes (Colombia). http://dx.doi.org/10.15425/redepub.36.2016.12

** Profesora-investigadora. Bachiller en Derecho y Ciencias Políticas por la Universidad Nacional Mayor de San Marcos (Lima, Perú). Maestría en Derechos Fundamentales y doctora en Derecho con orientación en Derecho Constitucional y Gobernabilidad por la Universidad Autónoma de Nuevo León (Monterrey, México). Actualmente directora del Posgrado de Humanidades y Ciencias Sociales de la Universidad Regiomontana (Monterrey, México) e investigadora asociada al Centro de Estudios Interculturales del Noreste (CEIN). Correo: despino@u-erre.mx.

*** Profesor-investigador. Licenciado en Sociología y doctor en Antropología Social por la Universidad de La Coruña (España). Actualmente director del Centro de Estudios Interculturales del Noreste (CEIN) en la Universidad Regiomontana (Monterrey, México). Miembro del Sistema Nacional de Investigadores (Nivel I). Correo: jdoncel@u-erre.mx. 
Introducción

La presente investigación tiene el propósito de hacer un pequeño pero innovador aporte respecto al desarrollo de unas mínimas bases empíricas y sociológicas en materia de estudios migratorios que, a su vez, contribuyan a abogar por una legislación adecuada a la realidad social. Con ello esperamos abrir el camino e incentivar la realización de nuevos estudios sociojurídicos que puedan ser instrumentalizados para trabajar en pro de que los derechos fundamentales sean aplicados de hecho en colectivos caracterizados por su extrema vulnerabilidad. En este sentido, en un primer acercamiento exploratorio pudimos observar que, a pesar del carácter de universalidad y generalidad de los derechos fundamentales, en México existe un colectivo completamente desprotegido para el cual estos derechos son un ideal: los migrantes indocumentados que cotidianamente cruzan el territorio nacional para llegar a Estados Unidos y, especialmente, para aquellos que deciden instalar su residencia de manera permanente en alguna ciudad mexicana. Principalmente, se trata de hondureños y, en menor medida, guatemaltecos, salvadoreños y nicaragüenses que, debido a la grave situación de ingobernabilidad que viven sus países, deciden arriesgar todo lo que tienen, tanto material como inmaterial, para alcanzar una mejor vida.

En cifras, la Comisión Nacional de Población ha estimado, con base en el Censo de Población y Vivienda de 2010 desarrollado por el Instituto Nacional de Estadísticas y Geografía (en adelante, INEGI), que en México residen 59.936 inmigrantes centroamericanos, los cuales constituyen el $6.19 \%$ de un total de 968.147 inmigrantes residentes en el país (Colegio de la Frontera, 2011). Con referencia a la migración en tránsito, Rodríguez (2014) calculó que el volumen del flujo de migrantes centroamericanos en tránsito irregular por México hacia Estados Unidos fue de aproximadamente 183.000 personas solo en el año 2012, constituyéndose como máximo desde el año 2007. Este dato, como explica el autor mencionado, es un aproximado que se cuenta a partir de las cifras oficiales de asegurados en México y Estados Unidos, aunque se estima que sean muchos más si se suma a aquellos que nunca son asegurados, como los que logran cruzar la frontera sin ser detenidos o los migrantes desaparecidos. En el mismo estudio señala que el migrante promedio es hombre, joven de entre 15 y 29 años, urbano, con escolaridad de entre 6 y 12 años y que no habla inglés. La población femenina solo representa el $13 \%$ del flujo de migrantes, con una mayor participación de salvadoreñas (p. 15).

La Encuesta sobre Migración en la Frontera Sur de México 2012 revela que la gran mayoría de migrantes hondureños y salvadoreños tenían como destino final Estados Unidos, mientras el $62 \%$ de migrantes guatemaltecos tenían como meta permanecer en México (Colegio de la Frontera, 2012). En el estado de Nuevo León, según cifras del INEGI, para el año 2010 se encontraban residiendo 1.794 inmigrantes centroamericanos. Referente a los migrantes en tránsito, no existen cifras oficiales por su condición de clandestinidad. Solo se cuenta 
con un informe que el albergue Casa Nicolás elabora desde 2012, donde se muestran cifras obtenidas del tránsito de inmigrantes que llegan a ese lugar, ubicado en el municipio de Guadalupe. El último informe (2014) señala que el número de migrantes recibidos de febrero a octubre de ese año fue de 1.112 personas (Casa Nicolás y Centro de Derechos Humanos, 2014).

No resulta fácil para una persona decidir dejar su hogar para emprender un largo viaje, que ni siquiera sabe cuánto durará y si regresará; sin embargo, la pobreza, la corrupción, la violencia $y$, en muchas ocasiones, la amenaza directa a la propia vida, obligan a miles de personas a dejar su país de origen en busca de subsistencia. Esta difícil decisión la tienen que tomar millones de personas alrededor del mundo todos los años, consolidando un fenómeno propio de la era de la globalización: la migración. Esta ha pintado un nuevo panorama mundial que plantea diferentes retos a la comunidad internacional, y de forma especial a los países destino y a los países expulsores de migrantes. México es, a su vez, país expulsor y receptor de migrantes, por lo que su política migratoria debe apuntar hacia ambos horizontes.

En las rutas que toman los migrantes indocumentados en el tránsito de México hacia Estados Unidos, el Estado está ausente. Lejos de garantizar los derechos de los migrantes que se internan de manera irregular en el país, el Estado no solo los deja desprotegidos ante todo tipo de peligros, sino que los convierte en la población más vulnerable a la violación de todos sus derechos $\mathrm{y}$, sobre todo, del propio derecho a la vida y a la integridad física. Por ello, son víctimas del crimen organizado (narcotráfico, tráfico de personas), de los malos agentes y autoridades del Estado, e incluso de los propios ciudadanos que se aprovechan de su desprotección para abusar de ellos impunemente (Delgadillo y Rojas, 2011, p. 26).

La gravedad de la situación es de tal magnitud que aun los organismos internacionales de protección de derechos humanos han Ilamado la atención a México sobre el tema. Existen amplios informes recientes de la Comisión Interamericana de Derechos Humanos (CIDH, 2011) y de la Oficina del Alto Comisionado de las Naciones Unidas para los Refugiados (ACNUR, 2009) que dan cuenta de ello e instan al Estado mexicano a respetar sus compromisos internacionales y a garantizar los derechos humanos de los migrantes y sus familias. Consideran dichas instancias que al ser universales, los derechos humanos no pueden ser limitados por una cuestión administrativa como la legalidad o no de la estancia de un migrante.

En el marco de la reforma integral en materia de derechos humanos, nació la nueva Ley de Migración (25 de mayo de 2011) con la que México ha buscado humanizar su política migratoria con respecto a la situación de los migrantes indocumentados, y coloca los derechos humanos, junto con la seguridad nacional, como vértices de este nuevo ordenamiento. Sin embargo, bien sabemos que una ley no obra por sí sola y que se necesita de toda una reforma estructural e institucional para que 
cumpla con sus objetivos. En pocas palabras, la realidad pone un reto muy difícil en el tema de la seguridad de los migrantes y de la salvaguarda de sus derechos fundamentales.

Ante este escenario adelantamos la presente investigación, cuyo objetivo general es analizar la forma en que la legislación vigente en materia de migración y derechos humanos responde o impacta la realidad social que cotidianamente viven miles de inmigrantes centroamericanos en situación de irregularidad administrativa y que residen, de forma transitoria o permanente, en el área metropolitana de Monterrey. La abrupta ruptura entre el aparato legislativo y la realidad social a la que se dirigen las leyes en materia de migración constituye un vacío que García Villegas (1993) trata de llenar a través de su concepto de "eficacia simbólica del derecho". El concepto de la eficacia simbólica, trabajado anteriormente desde la antropología social (tanto desde el estructuralismo de LeviStrauss como desde la antropología simbólica de Turner), es aplicado al ámbito del derecho por García Villegas, poniendo el acento en la preocupación por el poder de la ley para hacerse efectiva, poder que va más allá de su propia eficacia operativa y que viene dado por su misma capacidad para ser publicitada, generando en consecuencia determinadas representaciones y significaciones en los sujetos sociales a los que está dirigida.

Con todo lo anterior pretendemos también realizar un importante ejercicio interdisciplinar que contribuya a trascender la tradicional barrera que aísla las ciencias jurídicas de las ciencias sociales. En definitiva, planteamos aquí una doble problemática: la que se desenvuelve en el ámbito de lo social y de lo jurídico, y la que constituye una importante carencia en el ámbito académico. La interdisciplinariedad de esta propuesta viene dada principalmente por nuestro planteamiento metodológico mixto, dado que hacemos uso de métodos propios de las ciencias jurídicas (principalmente el análisis jurídico-legal), así como de un enfoque metodológico de carácter cualitativo a través del uso de herramientas como la observación participante, la entrevista en profundidad y la historia de vida, como veremos inmediatamente. Asimismo, la interdisciplinariedad de nuestro trabajo se percibe con claridad a través del encuadre epistemológico planteado, apoyándonos para ello en la definición de teóricos tanto del derecho como de la sociología.

\section{METODOLOGÍA}

Para el logro del objetivo general expuesto en el penúltimo párrafo de la introducción -y también para cubrir nuestro propósito de contribuir al desarrollo de una sociología jurídica-, ofrecemos un original planteamiento metodológico. Como acabamos de señalar, este se fundamenta en dos enfoques tradicionalmente separados pero necesariamente complementarios en tiempos de la globalización: el de las ciencias jurídicas y el de las ciencias sociales. Para abordar la problemática desde una perspectiva jurídica realizamos un análisis de contenido normativo en materia de derechos de los migrantes, a partir de la reforma cons- 
titucional sobre derechos humanos y la expedición de la Ley de Migración, ambas del año 2011. El análisis de contenido normativo se realizó en un plano comparativo con respecto a la Ley de Población de 1974. Con ello se obtuvo el panorama jurídico en el cual se enmarca nuestra problemática, el cual servirá para analizar la situación de los derechos humanos de los migrantes desde dos paradigmas jurídicos distintos: el positivista y el neoconstitucionalista.

En lo que se refiere a la aportación metodológica desde las ciencias sociales nos apoyamos en la superación que Giddens (1993) supuso de uno de los padres de la sociología, Emile Durkheim. Este auténtico cambio de paradigma se asienta sobre el paso de definir el objeto de estudio de las ciencias sociales como hecho social (Durkheim, 1986) hasta la preocupación esencial actual por la acción social y la intersubjetividad. Como ya se expuso ampliamente en el artículo "Nuevos retos y formas de la labor etnográfica a partir de la reconceptualización del objeto de estudio de la Antropología Social" (Doncel, 2012), este desplazamiento histórico de la conceptualización del objeto de estudio de las ciencias sociales no es más que el resultado natural o la exigencia necesaria para la superación de un enfoque epistemológico y metodológico demasiado rígido e inapropiado para el dinámico mundo globalizado que luchamos por comprender.

En clara consonancia con este planteamiento realizamos un amplio trabajo de campo de orientación cualitativa. Este carácter cualitati- vo de nuestro enfoque metodológico responde a la exigencia dada por la situación de clandestinidad que determina el fenómeno observado. En este sentido, es claro que cualquier abordaje sociológico o antropológico de una temática marcada por la irregularidad o la ilegalidad (prostitución, crimen organizado, bandas callejeras...) requiere una implicación etnográfica del investigador, con el fin de subsanar la carencia de datos estadísticos mediante una profundización en los significados que el actor social da a sus propias prácticas y discursos. Así pues, realizamos nuestro trabajo de campo a través de las herramientas metodológicas más propias de la etnografía: la observación participante, la entrevista en profundidad y la historia de vida.

Nuestras observaciones participantes se realizaron en diversos eventos, más o menos públicos, relacionados con el desarrollo de los derechos humanos de los inmigrantes indocumentados en Monterrey (eventos de asociaciones civiles defensoras de estos colectivos, congreso sobre valores con temática específica sobre migración irregular en México, presentación de un documental sobre esta problemática con asistencia de los propios protagonistas, etc.). También realizamos observaciones en los espacios urbanos donde estos inmigrantes conviven (desde las visitas a la Alameda de Mariano Escobedo, donde muchos de ellos esperan una oportunidad para obtener un trabajo esporádico, hasta eventos privados como bautizos o cumpleaños de la propia comunidad de centroamericanos en la ciudad). Por último, visitamos e interactuamos con los res- 
ponsables y los habitantes de dos centros de apoyo a este colectivo: Casa Nicolás y Casa del Forastero Santa Marta.

Para adentrarnos en el mundo de la intersubjetividad de los protagonistas de nuestra investigación realizamos cuatro entrevistas a informantes clave: a la directora de la Oficina de Atención al Migrante del estado de Nuevo León; a dos sacerdotes responsables de sendas casas de apoyo al inmigrante; y al padre Alejandro Solalinde, director del albergue Hermanos en el Camino. Además, realizamos entrevistas en profundidad a seis migrantes en tránsito y a tres inmigrantes residentes. Por último, utilizamos la metodología de historia de vida con una mujer hondureña residente en Monterrey que salió de su país hace siete años. Especialmente relevante será el seguimiento de este caso, pues es el único que posibilitó un contraste específico de los efectos antes y después del proceso de implantación de la Ley de Migración. Las sesiones, conversatorios o convivencias con esta persona y con su pareja se prolongaron durante los últimos tres años, por lo que hemos podido "vivir" desde su propia experiencia cómo se fueron sintiendo los efectos de la nueva ley.

\section{RESULTADOS}

Acorde con la estructuración metodológica explicada, presentamos aquí los resultados más relevantes de nuestra investigación. Tras el análisis jurídico del cambio de ley, continuamos con la perspectiva acerca de la problemá- tica ofrecida por nuestros informantes clave, para finalizar con la comprensión del fenómeno a través de la explicación de un caso específico desde el punto de vista de sus protagonistas. Es decir, proponemos aquí un análisis que va desde lo macrosociológico (análisis realizado en la introducción y necesariamente breve, dada la escasez de fuentes estadísticas), hasta lo microsociológico (con nuestro estudio de caso), pasando por el nivel mesosociológico (con la visión de organizaciones e instituciones con un contacto directo con el colectivo humano objeto de nuestra atención) y por la contextualización jurídica.

\section{A. Marco jurídico de la migración en México}

Actualmente, con la Ley de Migración de 2011 que reformó la Ley de Población de 1974, vivimos un periodo de transición en materia migratoria en México; sin embargo, esta no pudo causar efectos hasta que se expidió, en 2012, su reglamento. A partir de entonces, el marco jurídico migratorio en México se rige por a) la Ley de Migración de 2011; b) La Ley General de Población que regula temas de población, migración interna y algo de emigración; y c) la Ley de Refugiados y Protección complementaria. Además, en virtud de la reforma constitucional en materia de derechos humanos de 2011, también se aplica en materia migratoria el bloque de convencionalidad, el cual está conformado por los tratados internacionales en materia de migración y derechos humanos ratificados por México (Orozco, 2011). Este 
nuevo marco jurídico ha tenido y tendrá que lidiar con la actual realidad migratoria del país, es decir, ser un sitio obligado de tránsito y de destino de migrantes indocumentados contra los que sistemáticamente se cometen violaciones a sus derechos humanos (CIDH, 2013).

No hay duda de que la reforma constituye un significativo avance, pues implica el cumplimiento por parte de México de sus obligaciones internacionales en este campo. La reforma migratoria responde a la necesidad de humanizar la política migratoria mexicana al compás de la reforma constitucional en materia de derechos humanos. Por ello, la Ley de Migración de 2011 ubica en su centro a estos derechos y encuentra su fundamento último en la dignidad de la persona del migrante (Guevara, 2014, p. 86). Analicemos los cambios más trascendentes que supone esta nueva ley.

La Ley de Población de 1974 dificultaba la movilidad humana en el territorio mexicano (González-Murphy y Kolowsky, 2011). Con ella, refería Buchenau, “obtener autorización para trabajar legalmente en México se hizo más difícil que conseguir residencia permanente en Estados Unidos" (2001, p. 65). En consecuencia, la política migratoria mexicana fue duramente criticada en el exterior, por considerarse aún más excluyente que las políticas migratorias de los demás Estados del continente, incluido Estados Unidos. Esta ley promovía una inmigración selectiva dirigida a la población que demostrase buena salud física y mental, además de solvencia económica, que no fuese una amenaza al empleo de los mexicanos y que estuvie- ra interesada en integrarse al medio nacional (González-Murphy y Kolowsky, 2011). Desde esta perspectiva, la Ley de Población fue catalogada como un instrumento de vigilancia y control cuyo principio fundamental era la seguridad nacional, enfocada en regular la entrada, estancia, salida voluntaria y expulsión forzada de extranjeros en México.

A partir del año 2000 se inició el debate en torno a la necesidad de modificar la legislación en materia migratoria, ante las nuevas dimensiones que tomaba el fenómeno (Bustamante, 2002). En efecto, este cambio obedeció básicamente a dos razones: 1) el fenómeno migratorio en México había mutado y exigía una mayor participación del Estado, sobre todo para la protección y seguridad de la persona del inmigrante; y 2) la presión internacional de ser un país emisor y a la vez receptor de migrantes, lo cual exigía que la política migratoria para sus nacionales en el extranjero debía reflejarse, a su vez, en la que aplicaba a los extranjeros en su territorio (González-Murphy y Kolowsky, 2011).

La primera de estas razones hace referencia a las características propias de la población migrante que llega a México y las circunstancias de su llegada, estancia y salida del territorio. En relación con la población centroamericana que llega indocumentada a México, esta constituye actualmente el flujo más numeroso, con aproximadamente 183.000 inmigrantes de Guatemala, Honduras, Belice, El Salvador y Nicaragua en 2012 (Berumen y Narváez, 2012); aunque en realidad es un número mayor, no 
conocido oficialmente por su situación de clandestinidad. Además, en los últimos años se ha recrudecido un viejo problema social: la violación sistemática y generalizada de los derechos humanos de los migrantes indocumentados, de manos del crimen organizado e incluso de las mismas autoridades (PNUD, 2013).

La segunda razón apunta a la presión internacional para el diseño de una nueva política migratoria. Mientras el Gobierno mexicano exigía a Estados Unidos respeto por los derechos humanos de sus connacionales, el Gobierno americano lo acusaba de no brindar a los extranjeros en su territorio los mismos derechos civiles que exigía para los mexicanos. Esta incongruencia ha sido utilizada por varias organizaciones estadounidenses para exigir el recrudecimiento de las políticas migratorias en Estados Unidos (González-Murphy y Koslowsky, 2011, p. 10).

En 2006, el Gobierno mexicano reconoció oficialmente que la Ley de Población ya no resultaba efectiva para la imagen internacional que México quería proyectar al mundo (Calderón, 2012). Por ello, a partir de 2008 se dieron una serie de reformas aisladas para humanizar la política migratoria. Sin embargo, estas no fueron suficientes, teniendo en cuenta que aún se encontraba vigente el espíritu de la antigua ley cuyo principio de seguridad nacional impedía la armonización con el respeto irrestricto de los derechos humanos. Así, en mayo de 2011 entró en vigor la Ley de Migración, la cual en su artículo 2 adoptó como principios: a) el respeto irrestricto de los derechos humanos de los mi- grantes, b) la congruencia del Estado mexicano al garantizar los derechos que reclama para sus ciudadanos en el exterior, c) el abordaje del fenómeno desde un enfoque integral como corresponde a su complejidad, d) la responsabilidad compartida tanto de gobiernos nacionales como extranjeros, e) la hospitalidad y la solidaridad internacional, f) la facilitación de la movilidad internacional de personas con orden y seguridad, g) la complementariedad de los mercados laborales en la región, h) la equiparación de derechos entre nacionales y extranjeros al amparo del artículo 1 de la Constitución mexicana, i) el reconocimiento a los valores adquiridos de los migrantes, j) la unidad familiar y el interés superior de los menores de edad como principal criterio para autorizar la internación y estancia de extranjeros en el país y k) la promoción de la integración social y cultural entre nacionales y extranjeros. La incorporación legislativa de estos principios responde a las obligaciones internacionales asumidas en la Convención Americana de Derechos Humanos, así como a la adopción de las observaciones que la Comisión Interamericana hizo respecto a la situación de los inmigrantes indocumentados en México (CIDH, 2011) y las exigencias de la Convención Internacional sobre la protección de los derechos de todos los trabajadores migrantes y sus familias.

Atendiendo a estos principios, la Ley de Migración incorporó nuevas figuras no contempladas en la legislación anterior. Así, en el título II sobre "Derechos y obligaciones de los migrantes" incluyó una lista de derechos y obligaciones, entre ellas la de garantizar la igualdad de 
los extranjeros con respecto a los mexicanos, en el ejercicio de sus derechos, con independencia de su situación migratoria (art. 6). Esta "igualdad en derechos" abarca el acceso a los servicios educativos públicos y privados, la atención médica, la procuración e impartición de justicia, la autorización y registro de los actos referentes a su estado civil, la libertad de tránsito en el territorio nacional al limitar la obligación de comprobar la nacionalidad y la situación solo ante autoridad competente en los casos y bajo las circunstancias establecidas por la ley (arts. 8 a 11). Adicionalmente, busca proteger a las "poblaciones vulnerables" al establecer la obligación de la autoridad de tomar en cuenta la edad de los niños migrantes cuando sean ellos los involucrados en cualquier tipo de procedimiento (art. 11). También contempla el derecho del migrante a recibir información sobre sus derechos y obligaciones, además de los requisitos para su admisión, permanencia y salida del país, y sobre la posibilidad de solicitar el reconocimiento de refugiado, el otorgamiento de la protección complementaria, asilo político y determinación de apátrida (art. 13), así como el derecho de obtener de la autoridad migratoria la documentación que acredite su situación migratoria regular, cuando se satisfagan los requisitos exigidos por la ley (art. 58).

En materia de protección y asistencia a los inmigrantes, la ley faculta a la Secretaría de Gobernación para celebrar convenios con las dependencias y entidades de los tres niveles de gobierno a fin de implementar acciones tendientes a coadyuvar con los actos humanitarios, de asistencia o de protección a los migrantes, que realizan las organizaciones de la sociedad civil legalmente constituidas (art. 72). Además, se arroga al Instituto de Migración la carga de profesionalizar y certificar a su personal, de modo que su actividad se ciña invariablemente a los principios de legalidad, objetividad, eficiencia, profesionalismo, honradez y respeto a los derechos humanos (art. 22).

Como respuesta a la grave situación en materia de seguridad de los inmigrantes que transitan por México hacia Estados Unidos, la Ley de Migración determina que el Estado mexicano garantizará el derecho a la seguridad personal de los migrantes, con independencia de su situación migratoria (art. 66). En este sentido, la Secretaría de Gobernación tiene la facultad de crear grupos de protección de migrantes, además de celebrar convenios de colaboración con dependencias y entidades de los tres niveles de gobierno para efectos de establecer acciones de coordinación en materia de prevención, persecución, combate y atención a los migrantes que son víctimas de delito (art. 75). Finalmente, se tipifica el tráfico de personas (art. 159), agravado cuando se realice contra niños y adolescentes o se ponga en peligro la salud, integridad, seguridad o dé lugar a trato inhumano y degradante (art. 160), y la comisión de estos actos cuando el sujeto activo sea un servidor público (art. 161).

A pesar de las expectativas puestas por las asociaciones civiles en esta nueva ley, fue fuertemente criticada por considerarla meramente declarativa. El Grupo de Trabajo sobre Legislación y Política Migratoria (2012) señaló que 
incrementa la criminalización y la clandestinidad de la población migrante en situación irregular. Al respecto, el padre Alejandro Solalinde denunció, en el Cuarto Encuentro Mundial de Valores realizado en Monterrey, en 2012:

Los derechos humanos en México tienen un panorama desolador. Hay un desprecio práctico hacia ellos. Se dice en el discurso que los derechos humanos son indispensables para el desarrollo del Estado, pero en la práctica estos no son una realidad. Los seres humanos somos canjeables por dinero. Las políticas públicas en México están diseñadas para satisfacer intereses egoístas de los grupos de poder. Es preocupante la ausencia de los derechos humanos en la práctica. Es común manipular cifras de diagnóstico del respeto y protección de los derechos humanos para simular una realidad no existente (...) Para los migrantes hay derechos teóricos pero en los hechos estos derechos se les regatean o de plano se les niegan (...) La nueva Ley es más favorable a los derechos humanos que la antigua Ley de Población, pero igual tiene sus candados. La ley de migración no tiene un buen reglamento que permita hacer efectivos sus fines ni un adecuado apoyo financiero.

\section{B. Problemática desde la perspectiva institucional: el enfoque mesosociológico}

A Monterrey los inmigrantes centroamericanos indocumentados llegan, en su mayoría, en el tren de carga conocido como "la bestia", des- de San Luis Potosí, y los que tienen los recursos económicos llegan en camión. Monterrey es ciudad de tránsito hacia Estados Unidos de la Ruta 5-Norte, que sale desde Lecherías, en el estado de México, y va hasta Reynosa, Tamaulipas.

En su paso por Monterrey, los inmigrantes solo reciben asistencia de las Casas de Migrantes, que son residencias de la Iglesia católica ubicadas por toda la ruta del sur-norte. En el área metropolitana de Monterrey solo existen dos de estos albergues: en el centro la Casa del Forastero Santa Martha, dirigida por el padre Jesús Garza Guerra, y en Guadalupe la Casa Nicolás, dirigida por el padre Luis Eduardo Villarreal Ríos. Ambas pertenecen a la Pastoral de la Movilidad Humana, de la Arquidiócesis de Monterrey. El gobierno del estado no tiene implementada ninguna política de asistencia a los migrantes indocumentados. La licenciada Alejandra Ocádiz, directora de la Oficina de Atención al Migrante, del estado de Nuevo León, durante la primera etapa de nuestro trabajo de campo señaló:

Todo lo correspondiente a los extranjeros lo ve directamente el Instituto Nacional de Migración, que es la instancia competente (...) La ley federal da atribuciones al Instituto Nacional de Migración, y a dependencias federales, porque la regulación de la extranjería la ve directamente la Federación (...) Nosotros ya no tenemos obligación de andar persiguiendo o de remitir obligadamente a los extranjeros al Instituto Nacional de Migración. 
Para conocer la situación de los derechos humanos de los inmigrantes indocumentados en su paso por Monterrey se entrevistó al padre Jesús Garza Guerra, director de la Casa del Forastero Santa Martha y miembro vitalicio del Consejo Ciudadano de Atención al Migrante, quien trabaja con migrantes desde hace trece años. El padre Garza observó que los migrantes indocumentados no tienen ningún tipo de protección, que el Gobierno mexicano no se preocupa en absoluto por ellos. Para ejemplificar este abandono mencionó varios de los numerosos sucesos que ha documentado la prensa sobre desaparición, secuestro y ejecución de migrantes indocumentados de manos del crimen organizado. Se refirió a uno de los casos más mediáticos: la ejecución, el 25 de agosto del 2010, de 72 inmigrantes indocumentados en San Fernando, Tamaulipas, caso que a la fecha no ha encontrado respuesta de las autoridades. El padre Garza afirmó que no nos debe sorprender que la política migratoria mexicana no los tome en cuenta, pues cuando las autoridades hablan de migración se refieren sobre todo a la emigración de mexicanos a los Estados Unidos y a la protección de sus derechos, pero no a los inmigrantes que se encuentran aquí, en México. Llama la atención que en México, dice el padre Garza, los únicos que dan asistencia a los inmigrantes indocumentados son la Iglesia y algunas asociaciones civiles, pero en muchas ocasiones su actividad se ve entorpecida por las autoridades migratorias, las autoridades estatales y las municipales. Al respecto advirtió:

Ahorita hay un problema fuerte de migración en Lecherías. El Gobierno ha intervenido, la gente no quiso la Casa del Migrante, entonces en lugar de cuidarlos o apoyarlos, los echaron a la calle y ahora no tienen dónde cocinar. No tienen comida, no tenían aseo, se orinan en la calle, etc., y eso que se lo paga otra gente (...) El Gobierno cerró la Casa en lugar de protegerla (...) Y ahora están en carpas, ya sea cerca de los rieles y con un día que no pase el tren, ya de por sí llegan 1000 gentes diarias, entonces todos ellos se quedan ahí hasta que vuelve a retornar el tren para seguir adelante. Se ha originado un grave problema de salubridad pública.

Esta situación también fue denunciada por el padre Alejandro Solalinde, en su conferencia sobre Migración y Derechos Humanos durante el Cuarto Encuentro Mundial de Valores:

En materia migratoria (...) la sociedad civil tiene que suplir la responsabilidad del Estado. A las instituciones hay que presionarlas para que apoyen las actividades de la sociedad civil a favor de los migrantes, para que al menos, no entorpezcan sus actividades. Las autoridades no cumplen con su deber sin presión, por eso las asociaciones civiles que trabajan a favor de la migración han incidido en el cambio de leyes.

La Casa del Forastero Santa Martha es financiada por la arquidiócesis de Monterrey y recibe donaciones de particulares. Señala el padre Garza Guerra que estas casas no reciben apoyos gubernamentales, pues todo el presupuesto destinado a migración en el estado de Nuevo León se emplea en la ayuda a los 
migrantes mexicanos que viajan hacia Estados Unidos. Aparte de hospedar y dar asistencia, también recibe a centroamericanos para que colaboren con ellos. No les paga un sueldo, pero les da asistencia durante su estancia y aparte les ayudan a tramitar la forma migratoria como trabajador, a fin de que su permanencia sea legal y puedan trabajar para juntar dinero y seguir su camino hacia el norte.

La Casa del Forastero Santa Martha funciona en conexión con las otras casas de migrantes de la Iglesia católica en el sur del país y con las asociaciones civiles, a lo largo del camino que recorre el tren. Esto les brinda cierta protección a los migrantes, pues si desaparecen o se desconoce su paradero, ellos están pendientes de lo que les ocurra en el trayecto. Por ejemplo, al momento de la entrevista, el padre Garza Guerra recibió un correo electrónico del Centro de Orientación al Migrante de Oaxaca AC, donde se daba conocimiento de la desaparición de un menor guatemalteco de 12 años, quien había ingresado a México con visa de visitante local y había desaparecido desde el 25 de julio del 2012. De esta manera, ellos comparten información, colaboran con cualquier noticia o están pendientes de su llegada a la Casa.

Desde que ingresan a México, los migrantes centroamericanos saben que en cualquier iglesia católica a la que lleguen les van a dar razón de una casa donde recibirán apoyo. Este mecanismo funciona gracias al trabajo en redes. Por ejemplo, a la Casa del Forastero Santa Martha llegaban cada día, en 2012, cerca de 30 centroamericanos, en su mayoría hondureños; también salvadoreños y guatemaltecos. Muchos de ellos habían sido víctimas o testigos de diversos delitos por el camino: robo, agresión, secuestro, asesinato, violación, etc. No obstante, lo único que motiva a la gran mayoría de estos migrantes que Ilegan a Monterrey es reunir dinero suficiente para continuar su viaje y su proyecto de vida. Al respecto señala el padre Garza:

\begin{abstract}
Algunos migrantes, quizás, oyen que en Monterrey hay trabajo (...) Muchos de los que vienen dicen que no tienen dinero o no les van a ayudar para pasar, etc. y se quieren quedar aquí a trabajar. Ahí nosotros no les podemos dar ese servicio. Vienen a Monterrey a juntar dinero para seguir su camino a Estados Unidos o para devolverse.
\end{abstract}

Este es el caso de dos inmigrantes indocumentados, que al momento de la visita a la Casa del Forastero se encontraban colaborando en las labores diarias y accedieron a ser entrevistados. El primero de ellos, un joven hondureño de 26 años, dijo haber llegado a Monterrey a trabajar para juntar dinero y continuar su viaje a Estados Unidos. El padre Garza lo ha apoyado con el trámite de la forma migratoria, lo que le permite quedarse en la casa el tiempo que él tiene previsto: tres meses. Por las tardes labora en un taller de carpintería donde le pagan 20 pesos la hora, por no tener el permiso para trabajar. Señala el entrevistado que en este taller trabajan puros centroamericanos, todos ellos subpagados por su condición de "ilegales". El segundo entrevistado es también hondureño, de 45 años. En su caso, el trabajo ha 
sido esporádico. También afirmó que los centroamericanos son subpagados. Por esto, ya tiene en Monterrey un mes y aún no ha podido continuar su viaje.

La situación anterior nos da pie para plantear una problemática de mayores dimensiones humanitarias: la situación de los migrantes que deciden quedarse a residir en Monterrey. Estos, al resolver establecerse por tiempo indeterminado, pierden el apoyo de la única institución que vela por la protección de sus derechos. Como anota Villagómez (2015), el único refugio con el que pueden contar estos migrantes residentes es el de una incierta comunidad de connacionales que tejen sus redes de solidaridad y de apoyo mutuo en el nuevo espacio urbano.

Pero la organización comunitaria también se ve limitada por otra de las consecuencias de esta situación de irregularidad administrativa: la clandestinidad en la que viven tanto los migrantes en tránsito como los residentes. Los datos que maneja el Gobierno sobre este sector de la población son completamente inexactos. Entre ellos se encuentran perseguidos, mujeres violadas, secuestrados, que son obligados a incorporarse al crimen organizado, etc. El hecho de que su situación administrativa imposibilite su registro en estadísticas oficiales mínimamente confiables hace que estas personas no existan para el Estado. La problemática aquí es clara, pues según la premisa en cualquier Estado moderno "si no te cuentan, no cuentas". En palabras del padre Jesús Garza:
Sospecho que si se conociera realmente el número de inmigrantes indocumentados que transitan anualmente por el territorio mexicano, nos quedaríamos espantados de cuántos de ellos desaparecen por el camino y de la verdadera dimensión del problema.

A continuación introducimos un nuevo eje de análisis, que desarrollaremos en el siguiente apartado: ¿De qué manera es recibido por la sociedad determinado cambio en la legislación?, ¿el impacto de dicho cambio es vivido de forma real o la ley se mantiene únicamente en la esfera de lo ideal? Además de abrir estos interrogantes, el padre Jesús Garza menciona aquí el papel que juegan (o que deberían jugar) las asociaciones civiles e instituciones que realmente están fungiendo como protectores de los derechos de ciertas minorías.

A pesar de que la Ley de Migración se ha puesto más exigente con respecto a los derechos humanos de los migrantes, aún no se percibe que el problema haya disminuido. Esta ley nació gracias al trabajo conjunto de las asociaciones civiles y de la Iglesia, que se reunieron con diputados interesados en el tema. Sin embargo, al momento de redactar el proyecto final no se tomaron en cuenta las recomendaciones de este colectivo.

En definitiva, encontramos que en Nuevo León no hay ninguna institución gubernamental ni ningún programa oficial a favor de los migrantes indocumentados centroamericanos. Todo el trabajo asistencial (comida, vivienda, salud) la brindan las casas de migrantes de la Iglesia. 
Este papel asumido por la institución eclesial desvela una ausencia más que significativa del Estado mexicano en el cumplimiento de la legislación en su propio territorio. Veamos, a continuación, cómo es vivida esta situación por los propios protagonistas, inmigrantes indocumentados y residentes en el área metropolitana de Monterrey, así como el efecto que ha podido tener, varios años después de su implantación, la reforma migratoria de 2011.

\section{Problemática desde la perspectiva de sus protagonistas: el enfoque microsociológico}

La situación de los inmigrantes indocumentados centroamericanos que residen en Monterrey contradice por completo el principio de igualdad en derechos de los extranjeros y los mexicanos, que constituye el logro más relevante de la Ley de Migración de 2011. Como ya hemos señalado, sobre la situación de los derechos humanos de los residentes en Monterrey no se conoce casi nada por su condición de clandestinidad. Ellos viven, o tratan de sobrevivir, sin que haya un Estado que les garantice el ejercicio de sus derechos o que conozca, al menos, de su existencia y sus necesidades.

Veamos la situación de los derechos humanos de los inmigrantes indocumentados centroamericanos residentes en Monterrey, a través de un estudio de caso. Se trata de una mujer hondureña que reside desde hace cinco años, junto a su pareja, de origen salvadoreño, en el municipio de Juárez, área metropo- litana de Monterrey. Allí han nacido sus dos hijos. Carla (nombre ficticio para proteger su identidad), de 21 años, vino por primera vez a México hace siete años. Salió huyendo de Honduras por amenazas de muerte que recibió de parte de una pandilla. Jorge (nombre ficticio), de 25 años de edad, salió de El Salvador a los 19 años, huyendo de las amenazas de muerte recibidas por pertenecer a la Mara Salvatrucha. Ambos se conocieron en el camino hacia Estados Unidos, a donde lograron entrar y de donde fueron regresados a México.

En el último viaje que hicieron hacia Estados Unidos llegaron a Saltillo, pero como ella ya no quiso volver a intentar cruzar la frontera, pues estuvo a punto de morir arrollada por el tren, regresaron a San Luis Potosí. Ahí se estuvieron quedando en la casa del migrante de San Luis Potosí, donde una voluntaria les regaló 1.000 pesos y les recomendó mudarse a Monterrey y rehacer su vida aquí.

Con el dinero, tomaron el autobús con destino a Monterrey y llegaron a la casa del migrante San Nicolás, donde les han ayudado mucho. Carla considera que sin esa ayuda no habrían podido salir adelante, pues afirma que son los únicos que defienden a los migrantes en Monterrey.

A los ocho días de llegar a Monterrey, Carla encontró trabajo en una taquería ubicada en la Av. Eloy Cavazos, en Guadalupe. Al principio se negaron a darle el trabajo pues, como en todos lados, les tenían miedo por ser centroamericanos. Al respecto señala: 
La gente nos tenía miedo. Nosotros todo el día bajo el sol y buscando (...) Llegamos a una taquería a comer con el dinero de las pedidas que hacíamos en la calle. Al principio así sobrevivimos, de puras pedidas (...) Y llegamos a la taquería y no más nos notaron el acento y no nos querían atender (...) Y ahí había un anuncio que buscaban muchacha y yo pregunté, me dijeron que para mí no había [trabajo], que solo mexicanas (...) Pero yo terca regresé, estábamos desesperados, y al final sí me ocuparon.

Para contratarla no le pidieron papeles, pero sí le pagaban menos que a las empleadas mexicanas. "Ese es el precio que tienen que pagar por ser ilegales y centroamericanos", es lo que le dijo la patrona. El estar subpagada no representó un obstáculo para ser la empleada a la que más se le exigía en el trabajo. La patrona amenazaba constantemente su puesto de trabajo, le decía que si no le parecía el pago, que se buscara otro o que si faltaba un día o llegaba tarde, no se molestara en regresar. Finalmente la presión fue tan fuerte, que Carla no pudo más. Ella comentó:

Estas personas [los patrones] saben de la necesidad y de la desesperación de los migrantes indocumentados y aprovechan de eso para sacarles ventaja. Es una explotación y nosotros no nos podemos quejar en ningún lado porque nos agarran y nos deportan. Uno se siente impotente, hasta de rabia te pones a llorar. Yo ese día lloré y dije '¿es que en ningún lugar voy a poder vivir tranquila?'
A Jorge le pasó algo muy parecido. Él también pasaba penurias para encontrar trabajo, le exigían los papeles, era subpagado y, al igual que Carla, era al empleado al que más se le exigía. Su caso fue aún más crudo, pues lo despidieron porque quería legalizar su estancia ante Migración. Él trabajó durante dos años en una carbonera. Como se sentía estable, empezó a tramitar la forma migratoria de trabajador. Como Migración solicitaba muchos documentos, tenía que estar presentándose varias veces y pidiendo permisos. Entonces el empleador le dijo: “¿Quién crees que soy yo para andar arreglándote la vida? Además, con papeles, ya no me interesas" y lo corrió. Cuenta Jorge que en ese lugar trabajaban puros hondureños, todos subpagados, solo que ellos toleraban porque apenas se quedaban unas semanas. Después de esto le fue muy difícil volver a encontrar trabajo, pues se negaban a ocuparlo por la carencia de papeles, y por el miedo a que Migración los sancionara.

La situación de vulneración de derechos humanos de Carla y de Jorge se agravó cuando nació su primera hija. Cuenta Carla que cuando se dio cuenta de su embarazo no supo a dónde ir. No tenía dinero y en ningún hospital quisieron ayudarla por ser menor de edad e indocumentada. A pesar del apoyo de la Iglesia, en el hospital le dijeron: “Ahí espérate” y nunca llegaron por ella. Esto la enojó mucho y terminó peleando con ellos. Finalmente, gracias a la intervención de la Casa del Migrante, consiguió que la recibieran en una asociación civil de apoyo a mujeres embarazadas en situación de vulnerabilidad. Tuvo muchos problemas para ingresar 
ahí por ser hondureña, pues le decían que el beneficio era exclusivamente para mexicanas. Durante ese tiempo internada pidió permiso para legalizar su situación en Migración, a lo que la encargada del centro le respondió que si no regresaba en media hora le iban a echar a la policía. Así define esta etapa:

Era un infierno ahí, la verdad. Se aprenden muchas cosas ahí, pero el trato que me dieron fue indigno (...) Me sentía encerrada, no aguantaba. No me maltrataron, pero me discriminaban por ser hondureña. Me recibieron solo porque el padre Villareal habló con [menciona el nombre de la asociación] y [la señora] Alma batalló mucho por mí. Pero no me querían recibir ni ahí ni en ningún lado. Eran capaz de dejarme morir pariendo, pero de no recibirme ni encargarse de mí.

Pero el episodio más dramático de su estancia en Monterrey, y donde se evidencia el desconocimiento por parte de las autoridades del respeto a los derechos humanos de los inmigrantes indocumentados y de sus hijos mexicanos se dio en tres momentos: 1) durante el registro de nacimiento de la niña, 2) al acudir a los servicios de salud para atender a la menor y a la asistencia social, y 3) al intentar legalizar su estancia y la de Jorge en México.

Para registrar el nacimiento de la niña demoraron tres meses. Fueron muchas veces a Registro Civil, pero solo recibieron maltrato. En una ocasión los amenazaron con deportarlos. Por una parte, les pedían demasiados documentos, que ellos, por la forma como llegaron a México, obviamente no tenían. Luego les hacían esperar todo el día sin atenderlos. Finalmente les dijeron que solo los podían ayudar para deportarlos. Nunca registraban a la niña. Finalmente Migración firmó un papel para que ellos pudieran acceder al Registro Civil. Carla señala que el maltrato se dio por su condición de centroamericanos y de indocumentados. Se sintieron humillados, burlados por las autoridades, como si "no fueran personas". Señala Jorge que un registrador les dijo que no tenían los mismos derechos que un mexicano, que los indocumentados no tenían derechos. No registraban el nacimiento de la niña, pues según el registrador, Migración no les había "dado permiso".

El segundo momento fue al tratar de acceder a los servicios de salud para la niña. Ellos, por ser extranjeros en situación de irregularidad, no podían solicitar el Seguro Popular para su hija, a pesar de ser mexicana. Para ser atendida, tenía que tener una "tutora" mexicana que tramitara su cartilla. El problema se dio cuando Carla tuvo que pedir esa cartilla, que aparte de la niña, tiene registrados a los hijos menores de la tutora. Por manejarse la cartilla en otra familia, Carla no podía acceder a ella cada vez que la niña requería atención, por lo que solo la vio el pediatra una vez.

Finalmente, el tercer momento ocurrió al acudir al Instituto Nacional de Migración para regularizar su situación. Anota Jorge que en Migración no se preocupan por el inmigrante, no informan del trámite ni asesoran acerca de las posibilidades que existen para legalizarse en México. Comentó: 
Si no pagas la multa y las tasas, entonces no tienes nada que hacer ahí (...) no te escuchan ni te miran. Te atienden de mal humor como si les molestara que estés frente a ellos (...) A mí siempre me han tratado mal. Ya he ido como unas diez veces y siempre he recibido el mismo maltrato. Solo cuando la señora Alma va con nosotros, la escuchan, pero si no, nada. Solo les importa que pagues, aunque no tengas de dónde. Hasta me han llegado a decir que nosotros no existimos, que nuestra hija no existe, que somos un cero a la izquierda.

El problema básicamente está en que ninguno de los dos tiene pasaporte. Carla nunca lo tramitó porque salió a los 14 años de edad; Jorge sí, pero se lo robaron en el camino. Ahora ambos están tratando de reunir los documentos para solicitarlo y lo que más les pesa es el aspecto económico, pues en el caso de Jorge cuesta 700 pesos. En el caso de Carla, tendría que viajar a San Luis Potosí a tramitarlo y no tiene ni el dinero para el viaje ni los 70 dólares que debe pagar al consulado hondureño.

Lo que más les mortifica es que en Migración les han dicho que si a ellos los deportan, les quitan a la niña por ser mexicana y la mandan al Sistema de Desarrollo Integral de la Familia. Ahora ellos sienten que no pueden estar ni allá ni acá, pues si se quedan en Monterrey están como indocumentados y viven siempre con la amenaza de la deportación, pero si se regresan a sus países les quitan a la niña y además les espera una muerte casi segura.
Es que no puede ser que toda la vida estemos así. Pero ¿qué vamos a hacer? No podemos hacer nada, porque aquí el Estado no nos ayuda. En Migración y en Registro Civil nos han dicho que nosotros no existimos, tampoco la niña existe (...) ¿A dónde nos vamos a ir? No tenemos a donde ir y encima con una niña pequeña (...) Ni porque ella es mexicana la apoyan. La discriminan por ser hija de inmigrantes (...) Como madre siento muy feo.

Todos los acontecimientos narrados hasta este punto transcurrieron antes del año 2012, cuando fueron realizadas las primeras entrevistas. Después de tres años, al preguntar a Carla acerca del efecto que ha tenido el cambio de ley en su situación y en el respeto a sus derechos anteriormente vulnerados, encontramos un panorama no mucho más alentador. Por ejemplo, respecto al derecho a la personalidad jurídica, nos explica que los problemas para el registro de su nuevo bebé, de dos meses de edad, vienen porque en cada registro civil le exigen documentos diferentes (en uno un permiso migratorio normal y en otro un permiso provisional), ambos inviables para ellos, pues no se acercan a las oficinas de Migración principalmente por dos razones: por miedo a la deportación o a que les quiten a sus hijos y porque el dinero que les exigen para regularizarse es totalmente inalcanzable. En sus palabras:

No vamos [a Migración] porque tenemos miedo a que nos deporten. Porque la última vez que nosotros fuimos a ver cómo podíamos sacar el... los permisos migratorios... 
hace 3 años, hace 3 años fuimos... pues nos dio miedo porque nos dijeron que si en 15 días no teníamos el dinero para pagar la multa, pues que nos iban a agarrar y nos iban a deportar y la verdad ya tuvimos miedo y ya no quisimos volver a Migración.

Precisamente este miedo que impide que se acerquen a las autoridades migratorias es el causante de que no lleguen a conocer la actual oportunidad de regularizar su situación sin pagar las multas.

Respecto a la cuestión pecuniaria, además de los 3.000 pesos de multa que cada uno debía pagar a Migración, deben sumar lo que tienen que pagar al consulado de sus países para conseguir sus pasaportes -requisito exigido por Migración- y el consecuente traslado a San Luis Potosí en el caso de Carla, pues ahí está el consulado de su país. Aquí es donde el círculo vicioso se cierra, pues al no tener documentos, los explotan en el trabajo pagándoles el salario mínimo de subsistencia y, por tanto, nunca estarán en condiciones económicas de solucionar su situación administrativa. Como explica Carla:

El pago que él [su pareja] recibía era muy poco, no más nos alcanzaba para vivir, para comer diario. Nada más.... Hasta para las rentas batallábamos... entonces no podíamos sacar ni el pasaporte ni el permiso migratorio. No podíamos tener el dinero que allá nos pedían y no quisimos presentarnos por miedo a que nos deportaran y nos pudieran quitar a los niños.
Veamos esta situación laboral en la siguiente descripción de uno de los trabajos que ha tenido Carla, consecuencia directa de su condición de extranjera y de persona indocumentada.

He trabajado de mesera (...) en dos lugares (...) restaurantes. (...) No me pidieron papelería pero, lógicamente, con un sueldo muy bajo [diferente al que cobran las mexicanas en el mismo puesto]. $Y$ cuando se enteran que somos de otro país y le estamos trabajando, ahí nos ponen toda la mano encima (...) Nos pagaban 600 pesos a la semana, sin descanso... de domingo a domingo. No teníamos descanso ni nada. Si llegábamos cinco minutos tarde... claro, nosotras, porque habíamos dos hondureñas trabajando ahí... nos descontaban 50 pesos. Cada cinco minutos que llegábamos tarde eran 50 pesos que nos descontaban... y veníamos saliendo con un sueldo muy bajo y no teníamos descanso ni nada. Aparte el maltrato, que nos decía (...) cuando ven que el restaurante se llena empiezan a insultarnos (...) nos dicen 'peladas' o 'catrachitas'... porque nos dicen catrachas a nosotras las hondureñas... 'muévete catrachita de la chingada', 'hija de no sé qué'... nos tratan pésimo (...) Ellos tienen miedo a meter centroamericanos a trabajar porque piensan que migración les puede cobrar multa por tenernos a nosotros trabajando.

La situación laboral en el caso de Jorge tampoco ha mejorado, ni mucho menos. Así nos lo explica Carla:

Ahorita está de pintor, pero él cualquier trabajo que le salga él lo hace. Ahora está tra- 
bajando de pintor y trabaja... se va a las 6 de la mañana, a veces viene llegando a las 8, 9, 10 de la noche... a veces lo sacan hasta la 1 de la mañana trabajando, desde 6 hasta la 1 de la mañana (...) sin contrato (...) Y le pagan un sueldo muy bajo en relación a los demás [mexicanos]. Él ya aprendió a pintar y todo... el hombre este [el patrón] carga puros pintores y a él le da el sueldo más bajo y a los demás les sube más el sueldo (...) Es el único migrante (...) Al principio le estaban dando 1.200 [pesos a la semana], luego le subieron el sueldo a 1.500, luego le subieron el sueldo a 1.700 y se lo volvieron a bajar a 1.000 pesos... Y eso que trabaja, trabaja y trabaja y ahora ya no le pagan ya... Es más, no le están pagando... y él no se sale de ahí con la esperanza de que le paguen lo que le deben, porque sí le deben mucho dinero... y hemos estado sobreviviendo todas estas semanas con 500 pesos, que es lo que paga [como adelanto de lo que le debe] su patrón... a la semana.

En lo que se refiere al derecho a la salud, la nueva ley sí ha mejorado para los migrantes en tránsito, aunque no para los migrantes residentes que no han logrado regularizar su situación administrativa. Leamos la explicación de Carla acerca del cambio de la situación referente al derecho a la salud. Ella comienza subrayando la mejoría pero entendiendo que fue atendida como migrante en tránsito, a pesar de ser residente:

Ha mejorado mucho porque me ayudaron en el Centro de Salud con el embarazo del niño, ya me atienden mejor. Sabían mi situación que era extranjera, que era de Centroamérica y no me empezaron a cobrar las consultas ni los medicamentos. No, pues me trataron bien. Ya no me cobraban nada y me atendieron muy bien el embarazo. Me tenían en observación dos veces por semana (...) Ellos estaban pendientes para la hora que fuera a ser mi parto... estaban pendientes de a ver cómo ayudarme para que pudiera cubrir mi parto. No [costó nada el parto] porque una de las muchachas del centro de salud me dijo que estaban dando Seguro Popular por tres meses... y me dijo que fuera y lo sacara, fui y saqué el Seguro Popular (...) Lo estaban dando para migrantes por tres meses ná mas... y ese seguro me cubrió la cesárea y me sirvió de mucho... y no hace poco se me acaba de vencer (...) [Para renovarlo] me dijeron que no más sacando el permiso migratorio, no más así podía renovar el Seguro Popular, mientras no (...) Cubría lo que nos pudiera suceder en el camino [a los migrantes en tránsito].

Como evidencian estos últimos testimonios, la nueva ley no ha supuesto un cambio significativo en las condiciones mínimas de subsistencia de los migrantes que no pueden acceder a su regularización administrativa. Especialmente grave sigue siendo la situación de aquellos inmigrantes que, por diversas razones, deciden o se ven obligados a establecerse a medio o largo plazo en la zona metropolitana de Monterrey. No obstante lo anterior, el aspecto más positivo de esta ley viene dado por ciertas mejoras en ámbitos como el de la salud o el de la 
protección de los menores. Creemos y esperamos que, por lo menos, con estas iniciativas se muestre el camino a seguir para tener una sociedad más inclusiva, justa y acorde con las exigencias que marcan los derechos humanos.

\section{CONCLUSIONES}

1. El tránsito de política migratoria de securitización hacia una de tipo garantista implica, como principio fundamental, la equiparación de derechos entre extranjeros y mexicanos, con excepción de los de naturaleza política, y tiene como finalidad colocar a México a la vanguardia de la política migratoria internacional, además de cumplir con los estándares internacionales en materia de derechos humanos. Aun con las intenciones reformistas en materia de derechos humanos de la Ley de Migración de 2011, esta sigue siendo considerada meramente declarativa, pues para su efectiva implementación se requiere, además de los correspondientes cambios normativos, una reforma integral que vincule el ejercicio de la administración pública con énfasis en aquellos sectores que tienen relación directa con la población en cuestión.

2. Los derechos humanos de los inmigrantes centroamericanos indocumentados en Monterrey, tanto de los de tránsito como de los residentes, son en gran medida desconocidos y frecuentemente vulnerados por las autoridades mexicanas. En México, aún existe una fuerte tradición jurídica positivis- ta que genera que las leyes se interpreten exegéticamente y persiste en la mente de las autoridades las instituciones de la antigua Ley de Población. La arraigada cultura contramigración se percibe en los testimonios de los centroamericanos entrevistados, quienes manifiestan que son víctimas constantes de abusos, atropellos y hasta de criminalización. Este maltrato trasciende el ámbito institucional, pues también son victimizados por los ciudadanos y por el crimen organizado.

3. Ciertas organizaciones, asociaciones civiles y, sobre todo, agrupaciones eclesiásticas, fungen como los únicos organismos que palian la situación de desprotección que marca el camino de los migrantes. Estas organizaciones están, de hecho, llenando el vacío que deja un Estado que, o bien no tiene presencia efectiva para el alivio de la problemática 0 , incluso, se convierte en una parte más del problema.

4. Del análisis centrado en la situación de cotidiana vulneración de tres derechos básicos: derecho al trabajo, a la salud y a la personalidad jurídica, concluimos que de la vulneración del derecho a la personalidad jurídica, responsabilidad exclusiva del Estado, se deriva la vulneración de los otros derechos contemplados. Además, la mejoría en la defensa de estos derechos con la nueva ley únicamente se ha dejado sentir en el caso del derecho a la salud, lo cual solo se ha traducido en un beneficio real para los migrantes en tránsito, pero no para 
los residentes, que siguen siendo el sector en situación más crítica.

\section{Referencias}

1. Berumen, S. y Narváez, J. (2012). La migración centroamericana en tránsito irregular por México. Una aproximación a partir de registros administrativos migratorios $\mathrm{y}$ otras fuentes de información. En E. Rodríguez, L. M. Salazar Cruz y G. Martínez Caballero, Construyendo estadísticas: movilidad y migración internacional en México (págs. 89-134). México D. F.: Secretariìa de Gobernacioin; Subsecretariìa de Poblacioìn, Migracioìn y Asuntos Religiosos; Unidad de Poliitica Migratoria, Centro de Estudios Migratorios: Instituto Nacional de Migracioinn./Monterrey, Nuevo León, México: Tilde Editores.

2. Buchenau, M. (2001). Globalization and its contents. New York: New Press.

3. Bustamante, J. (2002). Migración internacional y Derechos humanos. México: Universidad Nacional Autónoma de México. Instituto de Investigaciones Jurídicas.

4. Calderón, L. (2012). Cambios en la agenda migratoria: entre el nuevo marco jurídico y las nuevas formas de migración en México. En T. Ramírez García y M. Ángel Castillo (Coords.), El estado de la migración. México ante los recientes desafíos de la migración internacional (págs. 19-50). México, D. F.: Consejo Nacional de Población.
5. Casa Nicolás y Centro de Derechos Humanos de la Escuela Libre de Derecho. (2014). Tercer informe sobre la situación de la población migrante centroamericana indocumentada en la zona metropolitana de Monterrey. México, D. F.: Escuela Libre de Derecho.

6. Comisión Técnica de las Encuestas sobre Migración en las Fronteras Norte y Sur de México. (2011). Situación de la emigración mexicana y la migración en tránsito irregular en México. México, D. F.: Colegio de la Frontera Norte/Consejo Nacional de Población/Instituto Nacional de Migración.

7. Colegio de la Frontera. (2012). Encuesta sobre migración en la frontera sur de México 2012. México, D. F.: Colegio de la Frontera Norte/Consejo Nacional de Población/Instituto Nacional de Migración.

8. Comisión Interamericana de Derechos Humanos. (2011). Observaciones preliminares de la relatoría sobre derechos de los migrantes de la Comisión Interamericana de Derechos Humanos a México. Washington D. C.: Comisión Interamericana de Derechos Humanos.

9. Comisión Interamericana de Derechos Humanos. (2013). Derechos Humanos de los migrantes y otras personas en el contexto de la movilidad humana en México. Washington D. C: Comisión Interamericana de Derechos Humanos.

10. Delgadillo, L. y Rojas, C. (2010). Informe sobre la situación general de los migran- 
tes y sus familias. Elaborado en ocasión de la visita a México del señor comisionado Felipe González, Relator Especial de Trabajadores Migratorios y Miembros de sus familias de la Comisión Interamericana de Derechos Humanos. México, D. F.: Instituto Tecnológico Autónomo de México.

11. Doncel, J. (2012). Nuevos retos y formas de la labor etnográfica a partir de la reconceptualización del objeto de estudio de la Antropología Social. Andamios. Revista de Investigación Social, 9(19), 11-30.

12. Durkheim, E. (1986). Las reglas del método sociológico. Madrid: Ediciones Morata.

13. García Villegas, M. (1993). La eficacia simbólica del derecho, examen de situaciones colombianas. Bogotá: Ediciones Uniandes.

14. Giddens, A. (1993). Las nuevas reglas del método sociológico. Buenos Aires: Amorrortu Editores.

15. González-Murphy, L. y Koslowsky, R. (2011). Entendiendo el cambio de leyes de inmigración en México. New York: Woodrow Wilson International Center for Scholars.

16. Grupo de Trabajo sobre Legislación y Política Migratoria. (2012). Opiniones preliminares del Grupo de Trabajo en torno a la iniciativa con proyecto de decreto por el que se expide la Ley de Migración [Comunicado de prensa]. 27 de enero del 2011. México.

17. Guevara, J. (2014). Conexiones entre los derechos humanos de las personas migrantes y la seguridad ¿Es posible afirmar que el derecho mexicano criminaliza la migración indocumentada? Cuestiones Constitucionales, (31), 82-117.

18. Instituto Nacional de Estadísticas y Geografía. (2010). Censo Nacional sobre Población y Vivienda 2010. Nuevo León.

19. Oficina del Alto Comisionado para los Refugiados de las Naciones Unidas. (2009). Informe presentado por el relator especial sobre los derechos humanos de los migrantes sobre su misión a México. Nueva York: Organización de las Naciones Unidas.

20. Orozco, J. (2011). Los derechos humanos y el nuevo artículo primero constitucional. lus, 5(28), 85-98.

21. Programa de Naciones Unidas para el Desarrollo. (2013). Informe regional de Desarrollo Humano 2013-2014. Seguridad ciudadana con rostro humano: diagnóstico y propuesta para América Latina. Nueva York: PNUD.

22. Rodríguez, E. (2014). Migración centroamericana en tránsito por México hacia Estados Unidos: diagnóstico y recomendaciones. México, D. F.: Instituto Tecnológico Autónomo de México.

23. Solalinde, A. (2012). Migración y derechos humanos. Conferencia en el Cuarto Encuentro Mundial de Valores. Monterrey.

24. Villagómez, J. (2015). Salvadoreños en Monterrey: reconstrucción de la identidad en una comunidad imaginada. En J. Doncel (Coord.), El mundo en Monterrey: migraciones y comunidades (págs. 71-96). México: Plaza y Valdés Editores. 